\title{
TOLERÂNCIA DE BACTÉRIAS DIAZOTRÓFICAS SIMBIÓTICAS À SALINIDADE IN VITRO
}

\author{
Tolerance of diazotrophic symbiotic bacteria to salinity
}

\author{
Rafaela Simão Abrahão Nóbrega ${ }^{1}$, Juciane Silva Motta $^{2}$, \\ Adão Marcelino Lacerda ${ }^{1}$, Fátima Maria de Souza Moreira ${ }^{3}$
}

\begin{abstract}
RESUMO
A busca de estirpes de bactérias diazotróficas simbióticas tolerantes à salinidade, em conjunto com a seleção de hospedeiros, tem por objetivo aumentar o desempenho da simbiose e manter a produtividade vegetal de forma sustentada em condições de estresse salino. Doze estirpes de bactérias diazotróficas de diferentes procedências foram estudadas quanto à tolerância a diferentes concentrações de $\mathrm{NaCl}$ em meios de cultura $79 \mathrm{e} \mathrm{LB}$. As estirpes que apresentaram maior tolerância à salinidade $\left(30 \mathrm{~g} \mathrm{~L}^{-1}\right)$ em meio 79 foram: BR 6806 e BR 4007, ambas de crescimento rápido isoladas de solos do Nordeste brasileiro, UFLA 03-51 e UFLA 03-65, de crescimento rápido e UFLA 03-84, de crescimento lento, sendo as três últimas oriundas da Região Amazônica. Essas também estiveram entre as mais tolerantes em meio de cultura LB. A estirpe UFLA 03-84, selecionada em trabalhos prévios por sua alta eficiência para caupi (Vigna unguiculata), pode ser indicada para estudos de inoculação, visando a aumentar o rendimento dessa cultura em solos salinos. Os meios de cultura 79 e LB foram eficientes para avaliar a tolerância relativa de rizóbio a $\mathrm{NaCl}$, mas o meio 79 é mais indicado, pois permite o crescimento de todas as estirpes. Pelos resultados, infere-se haver relação entre tolerância in vitro à salinidade e origem dos microssimbiontes, pois as estirpes BR 4007 e BR 6806, oriundas do Ceará, estiveram entre as mais tolerantes.
\end{abstract}

Termos para indexação: Rizóbio, $\mathrm{NaCl}$, estresse, Vigna unguiculata.

\begin{abstract}
Tolerance to salinity of diazotrophic bacteria and their host species could increase plant growth and sustainability in salt stressed soils. Twelve diazotrophic bacteria strains were studied regarding their tolerance to different $\mathrm{NaCl}$ concentrations in 79 and LB media. More tolerant $\left(30 \mathrm{~g} \mathrm{~L}^{-1}\right)$ strains in 79 medium were: the fast growers BR 6806 and BR 4007, isolated from northeast Brazil, UFLA 03-51 and UFLA 03-65, and slow growing strain UFLA03-84, being these last three isolated from Amazon region. These strains were among the most salt tolerant in LB medium. The high salt tolerance of strain UFLA 03-84, as well as its highest efficiency (biological nitrogen fixation) in cowpea symbiosis (Vigna unguiculata), indicates it can be assayed as inoculant to improve yields of this species at saline soils. Media 79 and LB were efficient to evaluate relative tolerance of rhizobia to $\mathrm{NaCl}$, however 79 medium is more suitable as it allows growth of all strains.
\end{abstract}

Index terms: Rhizobia, $\mathrm{NaCl}$, stresses, Vigna unguiculata.

(Recebido para publicação em 16 de dezembro de 2002 e aprovado em 16 de maio de 2003)

\section{INTRODUÇÃO}

A salinização do solo constitui uma das mais sérias formas de degradação dos recursos edáficos e, em áreas secas, caracteriza-se como um fenômeno complexo causado pela interação entre fatores biofísicos e sócio-econômicos. No Brasil, esses efeitos são mais intensos no meio rural da região semi-árida do Nordeste, em virtude de as características de clima, relevo, geologia, entre outros fatores, serem condições favoráveis à ocorrência de solos afetados por excesso de sais (MOTA e OLIVEIRA, 1999). Estudos de levantamentos de solos realizados nos Estados da Bahia ao Ceará, na escala de 1:500.000, indicam que uma área de aproximadamente $91.110 \mathrm{Km}^{2}$, representando $9,4 \%$ da área mapeada, está afetada por salinidade. Nessas áreas, predominam a policultura de subsistência, agropecuária extensiva e alguns focos de agricultura irrigada (PEREIRA, 1983).

$\mathrm{O}$ excesso de sais solúveis provoca uma redução do potencial hídrico do solo, resultando em menor capacidade de absorção de água pelas plantas. Essa redução, associada com os efeitos tóxicos dos sais, interfere inicialmente no processo de absorção de água pelas sementes, influindo também no desenvolvimento normal das plantas (REBOUÇAS et al., 1989) e sobre alguns processos biológicos, como a fixação biológica de nitrogênio, pois prejudica a eficiência da simbiose (SHEREEN et al., 1998).

\footnotetext{
1. Doutoranda e M.Sc., respectivamente, Bolsista do CNPq, Departamento de Ciência do Solo da Universidade Federal de Lavras/UFLA - Caixa Postal 37 37200-000 - Lavras, MG. rafaelanobrega@ufla.br, adaoml @terra.com.br

2. Bióloga, M.Sc., Departamento de Ciência do Solo/UFLA. jucianemotta@hotmail.com

3. Professora do Departamento de Ciência do Solo/UFLA, Bolsista do CNPq. fmoreira@ufla.b
} 
Assim como as plantas, as bactérias diazotróficas simbióticas apresentam grande variação na tolerância à salinidade. Essa tolerância ao estresse salino pode ser atribuída a variações de $\mathrm{pH}$, temperatura, fonte de carbono solúvel e à presença de solutos osmoprotetores (GRAHAM, 1992). Para bactérias dos gêneros Rhizobium e Bradyrhizobium, os efeitos prejudiciais dos sais são mais evidentes, particularmente em relação aos efeitos da concentração do íon específico do que ao efeito osmótico (ELSHEIKH, 1998), variando de acordo com a forma iônica presente e a tolerância da estirpe. Nesse contexto, o $\mathrm{NaCl}$ tem sido considerado bom indicador da tolerância de bactérias a sais (ABDELMOUMEN et al., 1999).

A busca de estirpes de bactérias diazotróficas simbióticas tolerantes à salinidade tem por objetivo, em conjunto com a seleção de hospedeiros adaptados a condições de estresse salino, aumentar o desempenho da simbiose e manter a produtividade vegetal de forma sustentada nessas condições. Para isso, testes in vitro em meio sólido podem ser utilizados, pois, além de permitirem a comparação de um grande número de microrganismos, são também rápidos e de custo relativamente baixo, possibilitando a identificação de estirpes tolerantes, antes da verificação de sua tolerância ao estresse salino em simbiose com o hospedeiro no campo. Assim, objetivou-se verificar diferenças entre estirpes de bactérias que nodulam leguminosas (isoladas de diferentes locais e espécies vegetais), com relação à tolerância a $\mathrm{NaCl}$, empregando método de avaliação in vitro nos meios de cultura 79 e LB.

\section{MATERIAL E MÉTODOS}

\section{Experimento 1: Tolerância de rizóbio à salini- dade em meio de cultura 79 modificado}

Doze estirpes de bactérias que nodulam leguminosas (isoladas de diferentes locais e espécies vegetais) (Tabela 1), sendo a maioria isolada de Vigna unguiculata, foram estudadas quanto à tolerância a $\mathrm{NaCl}$ em meio 79 (por litro: 10 g manitol; $0,1 \mathrm{~g} \mathrm{~K}_{2} \mathrm{HPO}_{4} ; 0,4 \mathrm{~g} \mathrm{KH}_{2} \mathrm{PO}_{4} ; 0,2 \mathrm{~g}$ $\mathrm{MgSO}_{4} .7 \mathrm{H}_{2} \mathrm{O} ; 0,1 \mathrm{~g} \mathrm{NaCl} ; 0,4 \mathrm{~g}$ extrato de levedura; $5 \mathrm{~mL}$ sol. 0,5\% em 0,2 N KOH de azul de bromothimol; $15 \mathrm{~g}$ Agar, pH 6,8) (FRED e WAKSMAN, 1928). As estirpes foram inoculadas em $50 \mathrm{~mL}$ de meio 79 líquido, com $\mathrm{pH}$ 6,8 e essas culturas foram mantidas sob agitação orbital por $105 \mathrm{rpm}$ a $28^{\circ} \mathrm{C}$. Após o crescimento por 3 dias para estirpes de crescimento rápido ou intermediário (que acidificam, alcalinizam ou não modificam o $\mathrm{pH}$ do meio de cultura) e por 6 dias para estirpes de crescimento lento (que alcalinizam o meio de cultura), sendo esses os tempos necessários para que as culturas de cada gênero atingis- sem a fase log, uma alíquota de $1 \mathrm{~mL}$ de cultura de cada estirpe foi transferida para tubos Eppendorf de 1,5 mL esterilizados, para centrifugação a $8.000 \mathrm{rpm}$, a $25^{\circ} \mathrm{C}$, por 4 minutos. O sobrenadante foi descartado e as células foram ressuspensas em $1 \mathrm{~mL}$ de solução salina estéril $\left(\mathrm{NaCl} 5,5 \mathrm{~g} \mathrm{~L}^{-1}\right)$ e centrifugadas novamente, repetindo o processo de lavagem das células por três vezes. Com esse processo, também realizado por Trannin et al. (2001), Matsuda et al. (2002a) e Nóbrega et al. (2004), objetivou-se a remoção de resíduos do meio de cultura do inóculo que poderiam resultar num falso crescimento positivo. Em seguida, alíquotas de $0,1 \mathrm{~mL}$ de suspensões de células lavadas de bactérias em solução salina foram inoculadas e espalhadas com alça de Drigalsky em placas que continham meio 79 modificado por adição de soluções $\mathrm{NaCl}$, que proporcionaram uma concentração final no meio de cultura de $1 ; 2 ; 2,5 ; 3 ; 10 ; 20 ; 30$ e $50 \mathrm{~g} \mathrm{~L}^{-1}$. Como tratamento-controle adicional, foi usado o meio de cultura 79 em sua composição original, que possui $0,1 \mathrm{~g} \mathrm{~L}^{-1} \mathrm{NaCl}$. Após a autoclavagem dos meios, aferiu-se o $\mathrm{pH}$ ajustandoos para 6,8 com solução de $\mathrm{HCl} 0,5 \mathrm{~mol}^{-1}$ esterilizada. As culturas foram incubadas a aproximadamente $28^{\circ} \mathrm{C}$ por 10 dias. Os tratamentos foram distribuídos inteiramente ao acaso, com três repetições. Para avaliar o comportamento das bactérias nas diferentes concentrações de sais (padrões de crescimento), foram atribuídos os seguintes valores: $0=$ sem crescimento; 1 = pouco crescimento; 2 = crescimento razoável, porém com distribuição heterogênea na placa; 3 = crescimento máximo, com distribuição uniforme por toda a placa, não diferindo do crescimento no meio com sua composição original, conforme trabalhos de Angle et al. (1993), Trannin et al. (2001) e Matsuda et al. (2002a).

Experimento 2: Tolerância de rizóbio à salinidade em meio de cultura LB modificado

As mesmas doze estirpes do experimento anterior (Tabela 1) foram testadas quanto à tolerância $\mathrm{a} \mathrm{NaCl}$ em meio Luria Broth- LB (por litro: $10 \mathrm{~g}$ Peptona de caseína; $5 \mathrm{~g}$ Extrato de levedura; $10 \mathrm{~g} \mathrm{NaCl} ; 15 \mathrm{~g}$ Ágar, $\mathrm{pH}$ 6,8) (SOMASEGARAN e HOBEN, 1994). Esse meio de cultura é utilizado para discriminar espécies de rizóbio (WANG et al., 1998; MARTINEZ-ROMERO et al., 1991). Como a composição original do meio LB apresenta $10 \mathrm{~g} \mathrm{~L}^{-1}$ de $\mathrm{NaCl}$, para este estudo, além dessa concentração, foram também testadas as seguintes concentrações: 1,$2 ; 2,5 ; 3 ; 20 ; 30$ e $50 \mathrm{~g} \mathrm{~L}^{-1}$. Como tratamentocontrole adicional usou-se o meio LB em sua composição original, porém, sem $\mathrm{NaCl}$. Utilizou-se a mesma metodologia do experimento anterior para instalação, condução e avaliação desse experimento. 
TABELA 1 - Estirpes de bactérias diazotróficas simbióticas testadas, com os respectivos gêneros, hospedeiros de onde foram selecionadas, tempo de crescimento, alteração de pH no meio de cultura 79 e local de origem.

\begin{tabular}{|c|c|c|c|c|c|}
\hline Estirpe $^{(1)}$ & Gênero & Hospedeiro & $\begin{array}{c}\text { Tempo de } \\
\text { Crescimento }^{(2)}\end{array}$ & $\begin{array}{c}\text { Reação do } \\
\text { pH do Meio }\end{array}$ & $\begin{array}{l}\text { Local de } \\
\text { Origem }\end{array}$ \\
\hline UFLA $03-24$ & nd. & Vigna unguiculata & Intermediário & Neutro & Amazônia \\
\hline UFLA 03-129 & nd. & Vigna unguiculata & Intermediário & Neutro & Amazônia \\
\hline UFLA 03-128 & Bradyrhizobium. & Vigna unguiculata & Lento & Alcaliniza & Amazônia \\
\hline UFLA 03-35 & Bradyrhizobium..$^{(3)}$ & Vigna unguiculata & Lento & Alcaliniza & Amazônia \\
\hline UFLA 03-84 & Bradyrhizobium..$^{(3)}$ & Vigna unguiculata & Lento & Alcaliniza & Amazônia \\
\hline UFLA 03-65 & nd. & Vigna unguiculata & Rápido & Acidifica & Amazônia \\
\hline UFLA $03-51$ & nd. & Vigna unguiculata & Rápido & Neutro & Amazônia \\
\hline UFLA 01-510 & Azorhizobium $^{(3)}$ & Sesbania virgata & Rápido & Alcaliniza & Minas Gerais \\
\hline INPA 0311B & Bradyrhizobium $^{(3)}$ & Centrosema pubescens & Lento & Alcaliniza & Amazônia \\
\hline BR2001 & Bradyrhizobium & Crotalaria juncea & Lento & Alcaliniza & África \\
\hline BR4007 & Sinorhizobium $^{(4)}$ & Prosopis juliflora & Rápido & Acidifica & Ceará \\
\hline BR6806 & Sinorhizobium $^{(4)}$ & Pithecellobium dulce & Rápido & Neutro & Ceará \\
\hline
\end{tabular}

${ }^{(1)}$ BR: estirpe da coleção da EMBRAPA-Centro Nacional de Pesquisa de Agrobiologia, Seropédica, RJ; INPA: estirpe da coleção do Instituto Nacional de Pesquisa da Amazônia; UFLA: estirpe da coleção da Universidade Federal de Lavras, Lavras, MG. ${ }^{(2)}$ Tempo para o aparecimento de colônias isoladas (dias): crescimento rápido, 1-3; crescimento intermediário, 4-5; crescimento lento, 6-10; crescimento muito lento, >10. ${ }^{(3)}$ dados não publicados. ${ }^{(4)}$ (MOREIRA et al., 1998).

\section{RESULTADOS E DISCUSSÃO}

Experimento 1: Tolerância de rizóbio à salinidade em meio de cultura 79 modificado

As concentrações máximas toleradas (CMT) de $\mathrm{NaCl}$ pelas estirpes, em meio de cultura 79, variaram de 2 até $30 \mathrm{~g} \mathrm{~L}^{-1}$ (Figura 1).

Não houve nenhuma estirpe que cresceu na concentração de $50 \mathrm{~g} \mathrm{~L}^{-1}$ de $\mathrm{NaCl}$. Os padrões de crescimento de todas as estirpes foram reduzidos com o aumento da concentração de $\mathrm{NaCl}$ no meio de cultura. Seis estirpes apresentaram CMT iguais ou inferiores a $10 \mathrm{~g} \mathrm{~L}^{-1}$, com $\mathrm{PC}=1$, nessa concentração. As estirpes UFLA 03-129 e UFLA 03-128 apresentaram CMT de $2 \mathrm{~g} \mathrm{~L}^{-1}$ e UFLA 03-35 apresentou CMT de $2,5 \mathrm{~g} \mathrm{~L}^{-1}$, sendo, portanto, as mais sensíveis ao estresse salino. A estirpe INPA 0311B, oriunda da Amazônia, teve CMT de 3,5 $\mathrm{g} \mathrm{L}^{-1}$. A BR 2001 isolada de Crotalaria juncea da África e a estirpe UFLA 03-24 da Região Amazônica tiveram CMT de $5 \mathrm{~g} \mathrm{~L}^{-1}$. Cinco estirpes toleraram até $30 \mathrm{~g} \mathrm{~L}^{-1} \mathrm{NaCl}$, apresentando PC =1: $\mathrm{BR} 6806$ e $\mathrm{BR}$ 4007, ambas de crescimento rápi- do isoladas do Nordeste brasileiro, UFLA 03-51 e UFLA 03-65 de crescimento rápido e UFLA 03-84 de crescimento lento, sendo essas oriundas da Região Amazônica.

Experimento 2: Tolerância de rizóbio à salinidade em meio de cultura LB modificado

Das doze estirpes testadas (Tabela 1), quatro não cresceram em meio LB: UFLA 03-128, UFLA 03-35, INPA 0311B e BR2001. Nesse meio, a fonte principal de carbono é a peptona de caseína, que representa um fator limitante para o crescimento de algumas espécies bacterianas, pois, nem todas têm capacidade de degradá-la em meio de cultura. Essa característica tem sido usada como diferencial para a descrição de novas espécies bacterianas, inclusive rizóbio (WANG et al., 1998; MARTINEZ-ROMERO et al., 1991).

Os padrões de crescimento em meio LB com as diferentes concentrações de $\mathrm{NaCl}$ testadas para cada estirpe encontram-se na Figura 2. 


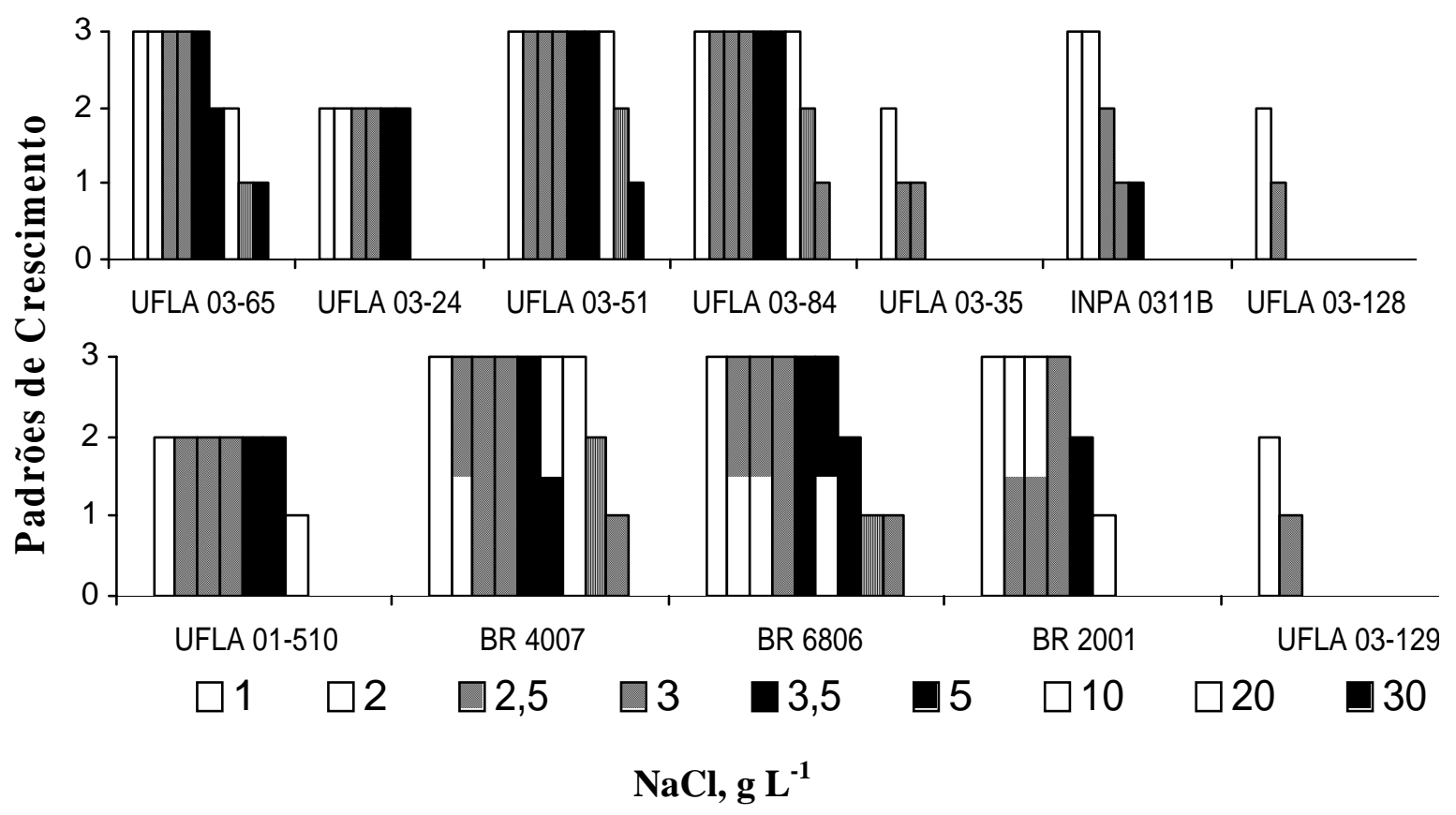

FIGURA 1 - Padrões de crescimento de estirpes de bactérias diazotróficas simbióticas expostas a diferentes concentrações de $\mathrm{NaCl}\left(\mathrm{g} \mathrm{L}^{-1}\right)$ em meio 79. 0 = sem crescimento; 1 = pouco crescimento; 2 = crescimento razoável, porém com distribuição heterogênea na placa; 3 = crescimento máximo, com distribuição uniforme por toda a placa, não diferindo do crescimento no meio com sua composição original.

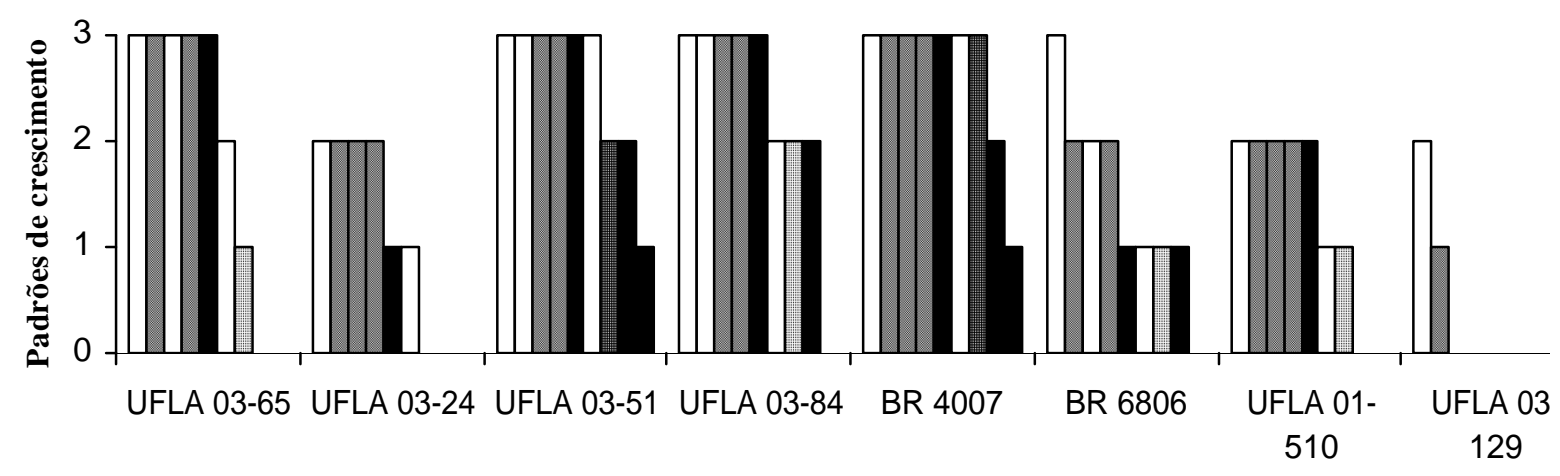

\section{$\square 1 \square 2 \square 2,5 \square 3 \square 3,5 \square 5 \square 10 \square 20 \square 30$ \\ $\mathrm{NaCl}, \mathrm{g} \mathrm{L}^{-1}$}

FIGURA 2 - Padrões de crescimento de estirpes de bactérias diazotróficas simbióticas expostas a diferentes concentrações de $\mathrm{NaCl}\left(\mathrm{g} \mathrm{L}^{-1}\right)$ em meio LB. $0=$ sem crescimento; 1 = pouco crescimento; 2 = crescimento razoável, porém com distribuição heterogênea na placa; 3 = crescimento máximo, com distribuição uniforme por toda a placa, não diferindo do crescimento no meio com sua composição original. 
As concentrações máximas toleradas de $\mathrm{NaCl}$ pelas estirpes variaram de 2 até $30 \mathrm{~g} \mathrm{~L}^{-1}$, como no meio de cultura 79. Do mesmo modo, não houve nenhuma estirpe que cresceu na concentração de $50 \mathrm{~g} \mathrm{~L}^{-1}$ de $\mathrm{NaCl}$ e houve redução do PC com o aumento da concentração de $\mathrm{NaCl}$. A maioria das estirpes que foram testadas, em ambos os meios, apresentaram CMTs semelhantes. As estirpes UFLA 03-84 e UFLA 03-65, apesar de apresentarem CMT menor no meio de cultura LB em relação ao meio 79, estiveram entre as mais tolerantes nesse meio.

Assim como para avaliar a tolerância de rizóbios a metais pesados (ANGLE et al., 1993; TRANNIN et al., 2001; Matsuda et al., 2002a), a utilização da avaliação do padrão de crescimento foi útil para diferenciar o comportamento de estirpes e isolados de bactérias simbióticas quanto à tolerância à salinidade. Embora seja uma metodologia que não possibilite quantificar as unidades formadoras de colônia/mL, possibilita qualificar o crescimento dos microrganismos em meio de cultura sólido, sendo um teste rápido de avaliação de grande número de isolados em laboratório.

A literatura é bem diversificada quanto a informações sobre as diferentes capacidades de bactérias diazotróficas, tanto associativas quanto simbióticas, em tolerar salinidade (CHEN et al., 1995; SHEREEN et al., 1998; RASA et al., 2001; TAMIMI, 2001; HUNGRIA et al., 2001; NÓBREGA et al., 2004), e as faixas de tolerância das espécies diazotróficas simbióticas observadas variaram de 0 a $60 \mathrm{~g} \mathrm{~L}^{-1} \mathrm{de} \mathrm{NaCl}$. Estudos com essa finalidade objetivam não só identificar estirpes potenciais para usos diversos, mas também auxiliar na caracterização das espécies bacterianas (CHEN et al., 2000; FRIONI et al., 2001; NÓBREGA, et al., 2004).

Em geral, espécies de rizóbio de crescimento rápido são mais tolerantes a altas concentrações salinas em meio de cultura, quando comparadas a espécies de crescimento lento, pois produzem mais polissacarídeos extracelulares, que envolvem as células bacterianas, diminuindo o contato da superfície celular com o meio salino, proporcionando maior resistência da célula bacteriana ao efeito osmótico (ELSHEIKH, 1998). No entanto, neste estudo, estirpes de crescimento rápido e lento estiveram tanto entre as mais tolerantes, quanto entre as mais sensíveis.

O uso de isolados efetivos e eficientes para inoculações em leguminosas em solos salinos dependerá do potencial desses em crescer e persistir nessas condições (HASHEM et al., 1998). Assim, estudos preliminares "in vitro" auxiliam na escolha dos isolados para estudos em campo. Essa relação foi demonstrada por Zou et al. (1995), que avaliaram o crescimento de Acacia ampliceps inoculada com rizóbio tolerante a $30,5 \mathrm{~g} \mathrm{~L}^{-1} \mathrm{de}$ $\mathrm{NaCl}$ e rizóbio sensível (tolerante a 2,93 $\mathrm{g} \mathrm{L}^{-1}$ ). Os auto- res verificaram que o tratamento inoculado com a estirpe tolerante foi menos afetado pelo estresse salino, apresentando maior nodulação e teor de $\mathrm{N}$ na planta. Matsuda et al. (2002b) também demonstraram haver relação entre a sobrevivência no solo e tolerância em meio de cultura para sais dos metais $\mathrm{Cu}, \mathrm{Zn}$ e $\mathrm{Cd}$. No entanto, parece não haver relação entre tolerância a sais e metais pesados, pois as três estirpes testadas neste trabalho e no de Matsuda et al. (2002b): UFLA 01-510 (Azorhizobium sp.), BR 2001 (Bradyrhizobium sp.) e BR 6806 (Sinorhizobium $\mathrm{sp}$.) apresentaram ordens crescentes de tolerância diferentes para $\mathrm{NaCl}$ (BR 6806 > UFLA 01-510 $>$ BR 2001) e metais pesados (BR 2001 > BR $6806>$ UFLA 01-510).

A estirpe UFLA 03-84, além de tolerar até $30 \mathrm{~g}$ $\mathrm{L}^{-1}$ de $\mathrm{NaCl}$, apresenta capacidade em nodular eficientemente em condições de campo o caupi (Vigna unguiculata), que é uma leguminosa muito cultivada no Nordeste brasileiro (LACERDA et al., 2004). Assim, o estudo da capacidade simbiótica dessa estirpe em solos salinos pode ser indicado, objetivando minimizar ou substituir da adubação nitrogenada no cultivo dessa espécie.

\section{CONCLUSÕES}

a) Os meios 79 e LB foram eficientes para avaliar a tolerância relativa de rizóbio ao $\mathrm{NaCl}$, havendo, de modo geral, relação entre a tolerância observada nos dois meios; no entanto, o meio 79 é mais útil, pois permite o crescimento de todas as estirpes.

b) Pelos resultados, infere-se que há relação entre tolerância in vitro à salinidade e origem dos microssimbiontes, pois as estirpes BR 4007 e BR 6806, oriundas do Ceará, estiveram entre as mais tolerantes, embora entre as estirpes mais tolerantes, houvesse também estirpes oriundas de solos não-salinos.

c) A estirpe UFLA 03-84, oriunda da Região Amazônica, é altamente tolerante à salinidade e pode ser indicada para testes de inoculação visando a aumentar o rendimento do caupi (Vigna unguiculata) em solos salinos.

\section{REFERÊNCIAS BIBLIOGRÁFICAS}

ABDELMOUMEN, H.; FILALI-MALTOUF, A.; NEYRA, M.; BELABED, A.; IDRISSSI, M. M. Effect of hight salts concentration on the growth of rhizobia and responses to added osmotica. Journal of Applied Microbiology, Oxford, v. 86, n. 6, p. 889-898, June 1999.

ANGLE, J. S.; McGRATH, S.; CHAUDRI, A. M.; CHANEY, R. L.; GILLER, K. Inoculation effects on legumes grown in soil previously treated sewage 
sludge. Soil Biological and Biochemistry, Great Britain, v. 25, n. 5, p. 575-580, 1993.

CHEN, W.; LEE, T. M.; LAN, C. C.; CHENG, C. P. Characterization of halotolerant rhizobia isolated from root nodules of Canavalia rosea from seaside areas. FEMS Microbiology Ecology, Amsterdan, v. 34, n. 1, p. 9-16, Oct. 2000.

CHEN, W.; WANG, E.; WANG, S.; LI, Y. Characteristics of Rhizobium tiansahnense sp. Nov., a moderately and slowly growing root nodule bacterium isolated from a arid saline environment in Xinjiang, People'sRepublic of China. International Journal of Systematic Bacteriology, Washington, v. 45, n. 1, p. 153-159, 1995.

ELSHEIKH, E. A. E. Effects of salt on rhizobia and bradyrhizobia: a review. Annals of Applied Biology, Lannham, v. 132, n. 3, p. 507-524, June 1998.

FRED, E.; WAKSMAN, S. A. Laboratory manual of general microbiology. New York: [s.n.], 1928. $141 \mathrm{p}$.

FRIONI, L.; RODRIGUEZ, M.; MEERHOFF, M. Differentiation of rhizobia isolated from native legume trees in Uruguay. Applied Soil Ecology, Amsterdam, v. 16, n. 3, p. 275-282, Mar. 2001.

GRAHAM, P. H. Stress tolerance in Rhizobium e Bradyrhizobium, and nodulation under adverse soil condictions. Canadian Journal Microbiology, Ottawa, v. 38, p. 474-484, 1992.

HASHEM, F. M.; SWELIM, D. M.; KUYKENDALL, L. D.; MAHAMED, A. I.; WAHAB, A.; HEGAZI, N. I. Identification and characterization of salt and thermotolerant Leucaena-nodulating Rhizobium strains. Biology and Fertility of Soils, Berlin, v. 27, p. 335341, 1998.

HUNGRIA, M.; CHUEIRE, L. M. O.; RAQUEL, G. C.; MANUEL, M. Preliminary characterization of fast growing rhizobial strains isolated from soyabean nodules in Brazil. Soil Biology \& Biochemistry, Oxford, v. 33, n. 10, p. 1349-1361, Aug. 2001.

LACERDA, A. M.; MOREIRA, F. M. S.; ANDRADE, M. J. B.; SOARES, A. L. L. Efeito de estirpes de rizóbio sobre a nodulação e produtividade do feijão caupi. Revista Ceres, Viçosa, v. 293, n. 51, p. 67-82, jan. 2004.
MARTINEZ-ROMERO, E.; SEGOVIA, L.; MERCANTE, F. M.; FRANCO, A. A.; GRAHAM, P.; PARDO, A. Rhizobium tropici, a novel species nodulating Phaseolus vulgaris L. Beans and Leucaena spp. Tress. International Journal of Systematic Bacteriology, Washington, v. 41, n. 3, 1991 .

MATSUDA, A.; MOREIRA, F. M. S.; SIQUEIRA, J. O. Tolerância de rizóbios de diferentes procedências ao zinco, cobre e cádmio. Pesquisa Agropecuária Brasileira, Brasília, v. 37, n. 3, p. 343-355, mar. 2002a.

MATSUDA, A.; MOREIRA, F. M. S.; SIQUEIRA, J. O. Sobrevivência de Bradyrhizobium e Azorhizobium em mistura de solo contaminadas com metais pesados. Revista Brasileira de Ciência do Solo, Viçosa, v. 26, n. 1, p. 249-256, jan./mar. 2002b.

MOREIRA, F. M. S.; HAUKKA, K.; YOUNG, J. P. W. Biodiversity of rhizobia isolated from a wide range of forest legumes in Brasil. Molecular Ecology, Amsterdam, v. 7, p. 889-895, 1998.

MOTA, F. O. B.; OLIVEIRA, J. B. Mineralogia de solos com excesso de sódio no estado do Ceará. Revista Brasileira de Ciência do Solo, Viçosa, v. 23, n. 4, p. 799-806, out./dez. 1999.

NÓBREGA, R. S. A.; MOREIRA, F. M. S.; SIQUEIRA, J. O.; LIMA, A. S. Caracterização fenotípica e diversidade de bactérias diazotróficas associativas isoladas de solos em reabilitação após a mineração de bauxita. Revista Brasileira de Ciência do Solo, Viçosa, n. 28, n. 2, p. 269-279, mar./abr. 2004.

PEREIRA, J. R. Solos salino sódico. In: REUNIÃO BRASILEIRA DE FERTILIDADE DO SLO, 15., 1982, Campinas. Resumos do Simpósio sobre Acidez e Calagem no Brasil. Campinas: Sociedade Brasileira de Ciência do Solo, 1983. p. 127-143.

RASA, S.; JORNSGARD, B.; ABOU-TALEB, H.; CHRISTIANSEN, J. L. Tolerance of Bradyrhizobium sp. (Lupini) strains to salinity, $\mathrm{pH}, \mathrm{CaCO}_{3}$ and antibiotics. Letters in Applied Microbiology, Oxford, v. 32, n. 6, p. 379-383, June 2001.

REBOUÇAS, M. A. A.; FAÇANHA, J. G. V.; FERREIRA, L. G. R.; PRISCO, J. T. Crescimento e conteúdos de $\mathrm{N}, \mathrm{P}, \mathrm{K}$ e $\mathrm{Na}$ em 3 cultivares de algodão sob condições de estresse salino. Revista Brasileira de Fisiologia Vegetal, Londrina, v. 1, n. 1, p. $79-85,1989$. 
SHEREEN, A.; ANSARI, R.; NAQVI, S. S. M.; SOOMRO, A. Q. Effect of salinity on Rhizobium sp., nodulation and growth of soybean (Glycine max. L.). Pakistan Journal of Botany, Pakistan, v. 30, n. 1, p. 75- 81, June 1998.

SOMASEGARAN, P.; HOBEN, H. J. Handbook for Rhizobia: methods in legume Rhizobium. New York: Springer Verlang, 1994.

TAMIMI, S. M. Genetic diversity and simbiotic effectiveness of rhizobia isolated from root nodules of commom bean (Phaseolus vulgaris L.) grown in the soils of the Jordan Valley. Applied Soil Ecology, Amsterdam, v. 19, p. 183-190, Oct. 2001.

TRANNIN, I. C. B.; MOREIRA, F. M. S.; SIQUEIRA, J. O.; LIMA, A. Tolerância de estirpes e isolados de Bradyrhizobium e Azorhizobium a zinco, cádmio e cobre in vitro. Revista Brasileira de Ciência do Solo, Viçosa, v. 25, n. 25, p. 305-316, abr./jun. 2001.

WANG, E. T.; BERKUM, P. V. van; BEYENE, D.; SUI, X. H.; DORADO, O.; CHEN, W. X.; MARTÍNEZ-ROMERO, E. Rhizobium huautlense sp. Nov., a symbiont of Sesbania herbacea that has a close phylogenetic relationship with Rhizobium galegae. International Journal of Systematic Bacteriology, Great Britain, v. 48, p. 687-699, 1998.

ZOU, N.; DART, P. J.; MARCAR, N. E. Interaction of salinity and rhizobial strain on growth and $\mathrm{N}_{2}$ fixation by Acacia ampliceps. Soil Biological and Biochemistry, Oxford, v. 27, n. 4/5, p. 409-413, 1995. 